\title{
Prevalence of Ovine Lung Worm in and around Jimma, South West Ethiopia
}

\author{
Mebrahten Gebrekidan, Kamil Kemal, Mukarim Abdurahaman* \\ Jimma University College of Agriculture and Veterinary Medicine, (JUCAVM), Ethiopia \\ *Corresponding Author: Mukarim Abdurahaman, Jimma University College of Agriculture and \\ Veterinary Medicine, (JUCAVM), Ethiopia
}

\begin{abstract}
A cross sectional study was conducted from November, 2017 to June, 2018 in and around Jimma to determine the prevalence of ovine lungworm infection, and to identify predominant lungworm species involved in the area. In this study feacal samples were taken from 293 sheep of all age groups, from both extensive and semi-intensive management systems, body condition score and both sexes were examined using modified Baerman technique to see the prevalence of lung worm by extracting L1 larvae from the processed feacal sample. The present study indicated that 67 sheep (22.9\% of the total 293 examined sheep) were found infected with different types of lung worm species. The infection rate between male and female animals showed nonsignificant difference ( $p>0.05)$ with prevalence of $23.4 \%$ in females and $22.3 \%$ in males. The prevalence of lung worm in different age groups $(23 \%, 27 \%$ and 29.9\% in animals with < 6 months of age, 6-24 months of age and in animals with $>24$ months of age respectively), age group showed no significance difference. There was a significant difference $(P<0.004)$ in the prevalence of lungworm infection with respect to management $14.8 \%$ in semi-intensive and $29.1 \%$ in extensive management systems were found respectively. In the case of body condition prevalence rates of $13.6 \%$ in good, $22.7 \%$ in medium and $29.9 \%$ in poor body conditioned animals) were found with $p=0.023$ with statistically significant association $(P<0.05)$. D. filaria was found the dominant lung worm species in the study area with 40 (59.7\%) of the total infection followed by M.capillaris (25.4\%). Mixed infection of these two species was found the least prevalent case in the study area involved only in $14.9 \%$ of the total prevalence rate. The result of this study indicated that lungworm infection in sheep is common parasite which induces heavy economic loss that needs greater attention due to its impact on sheep production of the study area. Therefore an appropriate control and prevention intervention should be carried out in order to reduce the losses associated with the parasite.
\end{abstract}

Keywords: Jimma Lung worm, Ovine, Prevalence

\section{INTRODUCTION}

Ethiopia possess the largest livestock population in Africa, with an estimated population of 7.8 million equines, 1 million camels, 47.5 million cattle, 39.6 million chickens, 26.1 million sheep and 21.7 million goats (CSA, 2009). Livestock production in Ethiopia contributes about 30-33\% of agricultural gross domestic product (GDP) and more than $85 \%$ of the farm cash income mainly through meat, milk, eggs, wool, hides and skins (Befekadu and Berhanu, 2000 and ESAP, 2003). Sheep and goats are the most numerous of man's domestic livestock. About 1.614 million sheep of the world which are about $65 \%$ are located in developing countries (Wilsmore, 2006).

Production and marketing of sheep and their products is a vital source of income, especially for small holders who do not have access to credit or farm income. Due to the small size, high reproductive capacity and rapid growth rate, small ruminants provide a more flexible short-term investment than cattle. Yet these species have received much less attention from research and development agencies than cattle (ILCA, 1990).

Sheep are important domestic animals in tropical livestock production systems. They play a great role in food supply, a source of income and foreign currency. Small ruminants provide as much as $30 \%$ of meat and milk consumed in sub-Saharan Africa and is found on small holdings throughout the continent. They are especially important in the more extreme climates of the world (Kouidri et al., 2013).

In Ethiopia, sheep are the dominant livestock providing up to $63 \%$ of cash income and $23 \%$ of food substance value obtained from livestock production (Bogale et al., 2012). The country has estimated 12 
million sheep together with its great variation in agro climatic zones represents a good reservoir of sheep genotypes. About $99.8 \%$ of the sheep are local breeds (CSA, 2013). Sheep are especially important in the more extreme climates of the world. In Africa, they are noted for their ability to convent low opportunity cost feed in to high value products including meat, milk, fiber, manure and hides (Wilsmore, 2006). Sheep play a vital role as sources of meat, milk and wool for smallholder keepers in different farming systems and agro-ecological zones of the country (FAO, 2009).

Due to the low input extensive management system an estimated, 132,000 tons of sheep meat is produced annually, providing more than $30 \%$ of all domestic meat consumption. Sheep also generate cash income to the farming community and significantly contribute to the foreign exchange earnings. In spite of the large population and importance of sheep, morbidity and mortality are high in the traditional agro-pastoral production system. Up to half of all sheep deaths and morbidity on farms in Ethiopian highlands are caused by pneumonia and endo-parasites (ILCA, 1990).

Respiratory lungworm parasites are the most common cause of high mortality and morbidity rates of sheep (FAO, 2006). Lung worm parasites are classified under the super family trichostrongyloidea and metastrongyloidea (Urquhart, 1996), which are causes of lungworm infection in ruminants (Schneider, 2000). Although these parasites are widely prevalent, the clinical signs they showed in infected sheep can be less obvious than signs of other ovine diseases (Hansen and Perry, 1994).

Epidemiological distribution of lung worm depends more on pasture contamination by carrier animals. Pasture infectivity is related to rainfall which stimulates the activity of both the larvae and the mollusk. Moisture is essential for the survival and development of the larvae.

Lungworm parasites are host specific and common in areas of mild high rain fall and abundant grass (Radostits et al., 2000). Adult dictyocaulus worms are slender, medium sized roundworms and up to 8 cm long (Dar et al., 2012).

Among ovine lung worm parasites dictyocaulus filarial is the most predominant lungworm species, followed by mulleries capillaries and protostrongylus refescens is the least prevalent (Kebede et al., 2014). The life cycle of ovine Lungworms have two forms, direct and indirect type. Direct form of life cycle is accompanied by dictyocaulidae and the indirect form of life cycle is accompanied by metastrongiloidae. The signs of lung worm infection (varminous pneumonia), range from moderate coughing with slightly increased respiratory rates to sever persistent coughing (Elsheikh and Khan, 2011).

Even though many anthelmentics are applied for the treatment of lung worm or verminious pneumonia this can't be as safety as control and prevention measures so that great control measures should be taken before ovine become infected with this respiratory disease. Control of these parasites is essential, for releasing the potential of sheep production. Lung worm is one of the respiratory sheep diseases that cause economical loss. For proper control the knowledge of parasitic diseases and rules for their control must be applicable to all regions by doing further researches and investigating the current status of the disease, study of each parasitic disease should not be limited to small areas (Radostitis, 1994).Therefore the objectives of this research were;

$>$ To determine the current prevalence of lungworm infection in ovine in and around Jimma.

$>$ To see the lung worm species those are found predominantly in the study area.

\section{Materials AND Methods}

\subsection{Description of the Study Area}

The study was conducted in Jimma zone, Southwest part of Ethiopia from November 2017 to June 2018 in and around Jimma town. Jimma town is the capital city of Jimma zone located in Oromia Regional Administration, $352 \mathrm{~km}$ Southwest of Addis Ababa at latitude of about 7013'-8056' N and longitude of 35052'-37037' E and at an elevation which ranges from 880 to 3360 metre above sea level. The study area receives a mean annual rainfall of about 1530 millimetre which comes from the long and short rainy seasons. The annual mean temperature ranges from about $12.1^{\circ} \mathrm{C}$ to $28^{\circ} \mathrm{C}$ (JZARDO, 2009). 


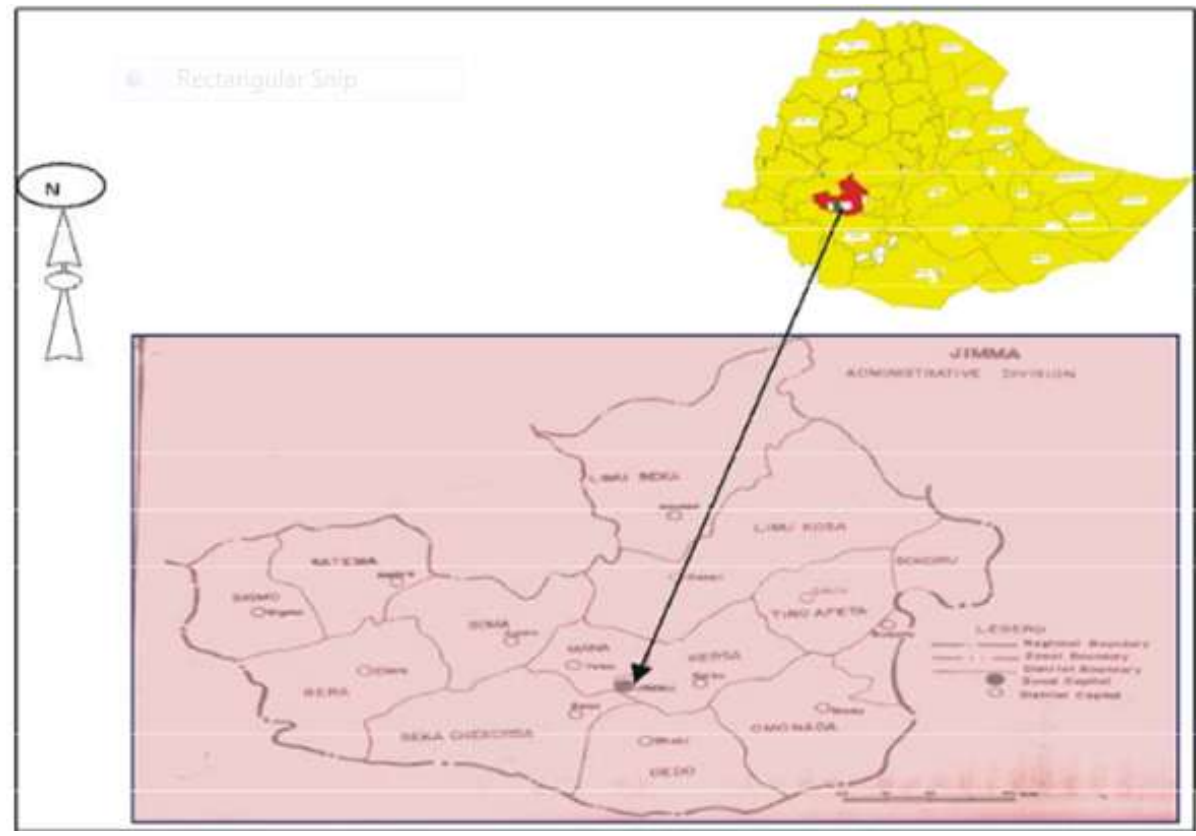

Figure5. Map of the study area

Source: Tolosa et al., (2010)

\subsection{Study Animals}

Fresh feacal samples were collected from randomly selected 293 sheep that are found both in semiintensive and extensive types of management. Animals from different kebeles found in Jimma town and the surroundings were studied coproscopically. In this study; animals of both sexes, animals found in all age groups, animals with poor, medium and good body conditions were considered. And sometimes fresh fecal samples were taken from animals that came to JUCAVM open air clinic.

\subsection{Study Design}

The study was a cross sectional type of study done to determine the prevalence of ovine lung worm infection by taking fecal samples from 293 sheep. From these 154 of them were females and 139 of them were males. Sex, age, management and body condition of animals were the explanatory variables used in the study. The above listed variables were recorded on the sample collection format paper.

\subsection{Sampling Method and Sample Size Determination}

The study was a cross-sectional type with simple random sampling technique to determine the prevalence of ovine lung worm infection in and around Jimma. A total of 293 sheep were randomly selected from Kebeles that are found in and around Jimma. The desired sample size for the study was calculated by using the formula given by Thrusfield (2005). The previous prevalence report of lungworm infection in sheep in and around Jimma town was reported 25.6\% (Dawit and Abdu, 2013). Therefore, an expected prevalence of $25.6 \%$ was taken to estimate the sample size. Then a total of 293 sheep were needed to determine the prevalence of lung worm in the study area by taking $95 \%$ confidence level and 5\% precision.

$$
\begin{aligned}
& \mathrm{N}=\frac{1.96 \operatorname{Pexp}(1-\mathrm{Pexp})}{\mathrm{d}^{2}} \\
& \mathrm{~N}=\text { required sample size } \\
& \text { Pexp = expected prevalence } \\
& \mathrm{d}^{2}=\text { desired absolute precision }
\end{aligned}
$$

\subsection{Sample Collection and Transportation}

After wearing disposable plastic gloves faecal samples were collected directly from the rectum of selected animals into a screw capped glass bottles (universal bottles) and packed in an icebox and then transported to JUCAVM Veterinary Parasitology Laboratory and each sample was processed by modified Bearmann technique as described by Charles and Robinson (2016). While collecting faecal 
samples, date, kebele sex, age, management and body condition of the sampled animals were properly recorded each day.

\subsection{Parasitological Technique}

In laboratory, isolation of lungworm larvae from feces was performed by using Modified Baerman technique. Ten to fifteen grams of fresh feces were weighed from each sample for the extraction of L1 larvae using Modified Baerman technique. Feces samples were fully enclosed in cheesecloth fixed with metallic stick (a graph) rest on the edges of the funnel glass. The glass was filled with Luke water until the sample became submerged by making sure that the corners of the cheesecloth did not hang over the edge of the funnel. The whole apparatus was left for 24 hours and then the sediment was examined under stereomicroscope (Anne and Gray 2006), and followed by larval identification using their morphology.

The larvae (L1) of Dictyocaulus filaria was seen larger in size, brown in colour with cranial cuticular knob and blunt tail while L1 of Muellerius capillaris is smaller in size, whitish in colour with " $\mathrm{S}$ " shaped tip and dorsal spine (Van Wyk, et al., 2004).

\subsection{Data Analysis}

The data was analysed in relation to sex, age, management, body condition and lung worm species. The data obtained was coded for the above variables and entered into Microsoft excel spread sheet. Statistical analyses was done on Statistical Package for Social Science (SPSS 20 version) software descriptive statistics was used to express prevalence and chi square $\left(\mathrm{x}^{2}\right)$ test was used to compare the association among variables. In all analysis the confidence level was held at $95 \%$ confidence interval and the desired absolute precision was set 5\%. Using the SPSS statistical software the differences were considered as significant when p-value is less than 0.05 and non-significant if 0.05 is less than that of p-value.

\section{RESUltS}

\subsection{Coproscopic Examinations}

A total of 293 sheep were examined in JUCAVM Veterinary Parasitology Laboratory using modified Baerman technique and first larval stage was extracted from each lung worm species. The result showed an overall prevalence of $22.9 \%$ ovine lung worm infection. Larval movement and identification of the lung worm species were done based on the morphology of the larvae by viewing the faecal samples under a microscope. D. filaria was found to be the highest prevalent lung worm species with $59.7 \%$ followed by $M$. capillaris $25.4 \%$ and $14.9 \%$ mixed infection. Though P. rufescens is one of the lung worm species that affects sheep it was not found in this study.

\subsection{Prevalence of Lungworm Infection Based on Sex}

An attempt was made to see if there was difference in the prevalence rate of lung worm between sex groups. The result indicated that there was difference in prevalence rate of lung worm between sex groups. From all sampled sheep 154 of them were females and 139 of them were males with prevalence rate of $23.4 \%$ in female and $22.3 \%$ in male sheep respectively. The association of the prevalence rate of lung worm with sex was computed with Chi-square test. There was no statistically significant difference $(\mathrm{P}>0.05)$ in the prevalence rate of lung worm between the two sex groups in sheep as indicated on (Table 1).

Table1. Sex basis prevalence of lung worm infection

\begin{tabular}{|l|l|l|l|l|l|}
\hline \multicolumn{1}{|c|}{ Sex } & Examined & Positive & prevalence & Chi-square value & p-value \\
\hline Male & 139 & 31 & $22.3 \%$ & 0.048 & 0.827 \\
\hline Female & 154 & 36 & $23.4 \%$ & & \\
\hline Total & 293 & 67 & $22.9 \%$ & & \\
\hline
\end{tabular}

\subsection{Prevalence of Lungworm Infection Based on Age}

Comparison of the prevalence of lungworm infection in different age group showed relatively higher prevalence was found in sheep with $6-24$ months of age (27.0\%). Sheep with $<6$ months of age (23\%) were found less infected by lung worm than sheep having 6-24 months age but higher than that of sheep with $>24$ months age $(18.3 \%)$. Age group was check whether it is significant or not by comparing 
the $p$ - value with 0.05 . Since ( $p>$ ) 0.05 age was not found significant in this study as indicated in the following table2.

Table2. Prevalence of lung worm infection based on different age groups

\begin{tabular}{|l|l|l|l|l|c|}
\hline \multicolumn{1}{|c|}{ Age } & \multicolumn{1}{c|}{ Examined } & Positive & Prevalence & Chi-square value & P-value \\
\hline$<6$ months & 100 & 23 & $23.0 \%$ & 2.079 & 0.354 \\
\hline 6-24 months & 100 & 27 & $27.0 \%$ & & \\
\hline$>24$ months & 93 & 17 & $18.3 \%$ & & \\
\hline Total & 293 & 67 & $22.9 \%$ & & \\
\hline
\end{tabular}

\subsection{Prevalence of Lung Worm Infection Based on Management}

Sheep from both extensive and semi-intensive types of management were considered and the overall prevalence of sheep managed under extensive management system (29.1\%) was found higher than in semi-intensive $(14.8 \%)$. This revealed that lungworm prevalence shows a significant variation $(\mathrm{P}<0.05)$ between the two management systems as can be seen from table four depicted below.

Table3. Prevalence of lung worm infection in different management systems

\begin{tabular}{|l|l|l|l|l|l|}
\hline Management & Examined & Positive & Prevalence & Chi-Square Value & P-Value \\
\hline Semi-intensive & 128 & 19 & $14.8 \%$ & 8.295 & 0.004 \\
\hline Extensive & 165 & 48 & $29.1 \%$ & & \\
\hline Total & 293 & 67 & $22.9 \%$ & & \\
\hline
\end{tabular}

\subsection{Prevalence of Lung Worm Infection Based on Body Condition}

Based on body condition, animals were categorized into three groups, namely good, medium and poor body conditioned animals. The lungworm infection rate according to the physical body condition was recorded to be $13.6 \%$ in animals with good body condition, $22.7 \%$ in those with medium body condition and $29.9 \%$ in animals with poor body condition. As the table below shows this result indicates a significance association $(\mathrm{p}<0.05)$ of lung worm infection in animals having different body condition scores. Generally lung worm is found more prevalent in poor body conditioned sheep.

Table4. Prevalence of lung worm infection based on body conditions of sheep

\begin{tabular}{|l|l|l|l|l|l|}
\hline Body Condition & Examined & Positive & Prevalence & Chi-Square Value & P-Value \\
\hline Good & 88 & 12 & $13.6 \%$ & 7.547 & 0.023 \\
\hline Medium & 88 & 20 & $22.7 \%$ & & \\
\hline Poor & 117 & 35 & $29.9 \%$ & & \\
\hline Total & 293 & 67 & $22.9 \%$ & & \\
\hline
\end{tabular}

\subsection{Prevalence of lung worm infection on the basis of lung worm species}

The examination of faecal samples collected from 293 randomly selected sheep using a modified Baermann technique revealed an overall lung worm prevalence of 67 (22.9\%). Dictyocaulus filarial was the predominant species in the study area 40 (59.7\%), followed by M.capillerius 17 (25.4\%), and simultaneous infection of sheep was found the least prevalent with10 (14.9\%)

Table5. Prevalence of lung worm infection based on different species of lung worm

\begin{tabular}{|l|l|l|}
\hline \multicolumn{1}{|c|}{ Lung worm species } & Number of positive animals & \multicolumn{1}{c|}{ Prevalence } \\
\hline D.filaria & 40 & $59.7 \%$ \\
\hline M.capillerius & 17 & $25.4 \%$ \\
\hline Mixed & 10 & $14.9 \%$ \\
\hline Total & 67 & $22.9 \%$ \\
\hline
\end{tabular}

\section{DISCUSSION}

Lung worm infection (verminous bronchitis, verminous pneumonia) is a chronic and prolonged infection caused by nematodes that affects the lungs of sheep. This disease results in substantial economic losses due to the reduction of growth rate, morbidity and mortality as the disease exposes animals to secondary bacterial infection. It also causes an economic loss due to organ condemnation and medication costs.

In this study, attempts were conducted to know the current over all prevalence of lung worm infection in and around Jimma. Coprological examination of faecal samples of 293 sheep was used to determine 
the overall prevalence of lung worm infection in the study area. Coprological examination of faecal samples revealed $22.9 \%$ of overall prevalence of lung worm infection in the study area. And the result of this study agrees with the results reported by Kassa and Abdu (2013) around Bahir Dar, Bekele and Shibbiru (2017) in and around Debre Berhan town, Bihonegn et., al (2017) in Minijar Shenkora woreda, North Shoa, and Dawit and Abdu (2013), in and around Jimma who reported 20.2\%, 18.3\%, 15.9\%, and $25.6 \%$ respectively. Being similar with the above researchers it disagrees with the reports of Yimer and Desie (2016) in North Ethiopia (46.6\%), Abdella et al. (2016), in Munesa District, East Arsi (66.67\%), Eyob and Matios (2013), in Asella province, Central Ethiopia (72.44\%). These results indicated that lung worm varies from place to place due to different reasons.

The possible explanation for such variations in the prevalence of lung worm infection in different study areas could be due to variation in agro-ecology of the study areas which favour or disfavours the survival of parasite's larvae in general and/or the presence or absence of snail intermediate host in case of M.capillaris in the study areas. Moreover, according to Bradford (2002), the occurrence of lungworms is associated with time of sampling, level of immunity of sampled animal's management practice of the animal and expansion of facilities like veterinary services.

In the current study on attempt was made to see the influence of sex on the overall prevalence of infection. And both sexes showed insignificant difference in susceptibility to infection with lungworms, even though the prevalence in female (23.4\%) was found relatively higher than in male $(22.3 \%)$. This finding agrees with the results of Kassa and Abdu (2013) around Bahir Dar, Yimer and Desie (2016), in North Ethiopia, Bekele and Shibbiru (2017) in and around Debre Berhan town and Eyob and Matios (2013), in Asella province who reports higher prevalence in female than in male. This higher prevalence rate of lung worm infection in female animal could be due to the fact that the resistance to infection is abolished at the time of parturition and during early lactation in female animals. But this contradicts with Bihonegn et al., (2017) in Minijar Shenkora woreda, North Shoa, who reported higher prevalence of lung worm infection in males than females. These variations may be due to the improper distribution of sample selection between the two sexes. Other possible reason for this can be because of great care of owners to their female sheep than to their male sheep.

The level of prevalence was compared between animals of different age groups. Though the age group result was not statistically significant different prevalent rates in different age groups was found. Accordingly this study showed that the least prevalent of lung worm infection was found in animals of greater than 24 months age (18\%) but the highest was recorded in animals at the interval between six months and twenty four months (two years old) with $27 \%$ prevalent rate. Animals with less than six months age laid at the middle position with $23 \%$ prevalent. The difference may be as a result of immunity variation which helps to expel adult lung worms.

Animals kept both in semi-intensive and extensive management systems were studied. There was high significant difference between the prevalence rate of lung worm infection of sheep in the two management systems $(\mathrm{P}<0.05)$ table 4 . In this study $29.1 \%$ prevalence rate of lung worm infection was determined in animals managed extensively, comparatively very low prevalence rate, $14.8 \%$ was found in animals kept under semi intensive management system. This result is in line with reports of Ibrahim and Godefa (2012), in Mekelle town, Sissay (1996) in and around Bahir Dar, Bekele and Shibbiru (2017) in and around Debre Berhan town and Mekonen et al., (2011) in Gondar, and this could possibly be associated with receiving an inadequate keeping and poor conditions of sheep in extensive management system and since grazing they have high probability of exposing to the larvae of the disease causing agent and to the snails; animals under well nourishment and watering lead to be less risk of helminthic infection (ILCA, 1993). But this result is opposite from the result found by Dawit and Abdu (2012) who reported higher prevalence of lung worm infection in sheep under semi intensive management system (28.6\%) than in extensive management system $(26.0 \%)$.

An attempt was made to see the influence of body condition on the overall prevalence of lung worm infection in sheep and body condition was found statistically significant $(p<0.05)$ as indicated in table 5 above. The highest prevalence rate of lung worm infection (29.9\%) was found in poor body conditioned animals while the prevalence rate of good body conditioned animals (13.6\%) holds the least. In this study animals with medium body condition were found with medium prevalence rate of lung worm infection. This finding is in agreement with studies reported by Bihonegn et al., (2017), Yimer and Desie (2016) and Abdella et., al (2016), they all reported higher prevalence rate in animals 
with poor body condition, but the study disagrees with the findings of Dawit and Abdu (2012) who reported higher prevalence rate in animals with good body condition.

This difference might be due to poor body conditioned animals are easily exposed to infectious and non-infectious diseases than medium and good body conditioned animals. Because of these and other related reasons their immune system becomes suppressed and less competent on feeding than medium and good body conditioned animals and hence they faced to a problem in tolerating and getting rid of the lung worm larvae this may be followed by malnutrition and concurrent infections like other gastrointestinal nematodes or infectious diseases like bacterial infections. Poorly nourished sheep appear to be less competent in getting rid of lungworm infection and the infestation with a parasite by itself might results in progressive emaciation of the animals (Teffera, 1993).

Attempt was also done to see what species of lung worm are found in the study area and which species is predominantly present in the area. Accordingly $D$. filaria was found the dominant species of the area with the prevalence rate of $59.7 \%$ followed by M.capillaris which covers $25.4 \%$ of the total lung worm infection in and around Jimma. This result agrees with the studies reported by Yimer and Desie (2016), Abdella et al., (2016), Bihonegn et al., (2017), Kassa and Abdu (2013), Bekelle and Shibbiru (2017). All the above researchers reported higher prevalence of D.filaria and M.capillaris respectively.

Here some animals were also found concurrently infected (mixed infection with the two species at the same time). This holds $14.9 \%$ of the total infection with all species of lung worm. Though P.refuscens is one of the common lung worm species that causes lung worm infection in sheep it was not found in this study. This result also coincides with the study made by Yimer and Desie (2016) who reported $18.9 \%$ of D.filaria, $14.2 \%$ of M.capillaris and $11.1 \%$ of mixed infection.

This marked difference in between might be due to difference in life cycle of those lung worm species. D.filaria has direct life cycle and also takes less time to reach the infective stage and after ingestion; the larvae can appear in the feces in a few weeks (Souls, 1982). Compared with D.filaria the transmission of M.capilaris is epidemiologically complex event involving the host, parasites and intermediate host relationship, furthermore the development of L1 to infective stage larvae in the snail takes 2- 3 weeks, and 5-6weeks are needed to be prevalent in the final host. The probability of infection and transmission of M.capillaris would be much lower than D.filaria (Urquart et al., 1996).

\section{CONCLUSiOnS}

The result of this study showed that lungworm is one of the major helmenthosis of sheep in and around Jimma, which is affecting the health and production performance of sheep in this area. The coproscopical examination of the current study revealed that $22.9 \%$ of the examined sheep were infected with D.filaria, M.capillaris or mixed infection of the two species of lungworms. The prevalence of lung worm infection is significantly higher in animals managed extensively, in animals with poor body condition but animals kept under semi-intensive type of management were found less infected with lung worm. This study also revealed that animals with good to medium body condition were less infected with lung worm. Though this disease affects all age group animals it was found more prevalent in animals from 6 months to twenty four months old. This also indicated that Dictocaulos flaria is the dominant lung worm species present in and around Jimma with prevalent rate of more than two times and four times than of M.capillaris and mixed infection respectively. Lung worm were found more prevalent in female sheep than in male sheep with non-significant scientific difference. The following recommendations are forwarded based on the above conclusions. Regular deworming with effective antihelmintic should be routinely practiced in the area.

\section{REFERENCES}

[1] Abdella Shenba, Abdela Ahmed, Abduselam Ali, Daniel Bululta, Fikre Nigatu, Beshatu Ferade, Lama Yimer (2016) Prevalence of Ovine Lungworms In Munesa District, East Arsi, Ethiopia; 8:1-7.

[2] Anne, M. and A. Gray, 2006. Veterinary clinical parasitology. 7 ed. Australia, Blackwell Publishing Company, pp: 11-14.

[3] Befekadu K, Berhanu N (2000) Annual Report of the Ethiopian Economy. Addis Ababa. Ethiopian Economic Association 1199-2000.

[4] Bekele, T. and Shibbiru, T., 2017. Prevalence of Ovine Lungworm and Associated Risk Factors in and Around Debre Berhan Town, Ethiopia. Int J Vet Health Sci Res, 5(6), pp.190-195. 
[5] Bihonegn, T., Bizuwork, D., Minda, S., Taddese, M., Tesfaye, W. and Abrham, F., 2017. Study on the Prevalence of Ovine Lungworm Infection in Minijar Shenkora Woreda, North Shoa, Ethiopia. Int. J. Adv. Res. Biol. Sci, 4(7), pp.164-168.

[6] Bogale, B., Ebre, A. and Melaku, A., 2012. Ovine lungworm infection: prevalence, species composition and associated risk factors in Dessie Zuria District, Northeastern Ethiopia. African Journal of Basic and Applied Sciences, 4, pp.73-76.

[7] Bradford P (2002), Large Animal Internal Medicine. In: Veterinary Medicine: A text book of the disease of Cattle, Sheep, Pigs, Goats and Horse. 9th edn.

[8] Charles, M.H. and Robinson, E., 2006. Diagnostic veterinary parasitology for veterinary technicians.

[9] CSA (Central Statistical Agency), 2009. Agricultural survey. Report on livestock, poultry and bee hives population, private peasant holdings, Addis Ababa Ethiopia.

[10] CSA, (2013). Agricultural Sample Survey, 2012/13 (2005 E.C.), Volume II: Report on Livestock and livestock characteristics (Private peasant holdings). Statistical Bulletin-570. Addis Ababa: Central Statistical Agency (CSA), Federal Democratic Republic of Ethiopia; 2013.

[11] Dar, L.M., Darzi, M.M., Mir, M.S., Kamil, S.A., Rashid, A., Abdullah, S., Hussain, S.A., Bhat, A.A. and Reshi, P.A., 2012. Prevalence and Pathology of Lung Worm Infection in Sheep in Kashmir Valley, India. Journal of Animal Science Advances, 2(8), pp.678-685.

[12] Elsheikh, H. M. and Khan, N. A. (2011). Essentials of Veterinary Parasitology. 1st ed. Caister Academic Press, Norfolk, UK. Pp 52-69.

[13] ESAP (2003) Proceeding of the 10th annual conference of the Ethiopian society of animal production Addis Ababa, Ethiopia.

[14] Eyob, E. and Matios, L., 2013. The prevalence and risk factors associated with ovine lungworm infestation in the Asella province, Central Ethiopia. Journal of Parasitology and Vector Biology, 5(8), pp.116-121.

[15] FAO (1986) Small ruminant production in the developing countries, In proceedings of an expert consultation held in Sofia, Bulgaria.

[16] FAO (Food and Agricultural Organizations of the United States) FAOSTAT data; 2009.

[17] Hansen, J. and Perry, B., 1994. The epidemiology, diagnosis and control of helminth parasites of ruminants. A handbook.

[18] Ibrahim, N. and Degefa, Y., 2012. Prevalence of Ovine Lung Worm Infection in Mekelle Town, North Ethiopia. Int. J. Vet. Med, 9(1), pp.1-15.

[19] ILCA (International Livestock Centre for Africa). (1990). ILCA Annual Report 1989. ILCA, Addis Ababa, Ethiopia, p.37.

[20] International Livestock Centre for Africa (ILCA) Annual report and program highlights, ILCA, Addis Ababa, Ethiopia; 1993; 29-31.

[21] JZARDO, 2009. Jimma zone agriculture and rural developmental office. Annual report.

[22] Kassa, T. and Abdu, M., 2013. Prevalence of Ovine Lung Worms-Around Bahir Dar, East Africa, Ethiopia. Acta Parasitologica Globalis, 4(3), pp.71-79.

[23] Kassai, T., 2006. Nomenclature for parasitic diseases:cohabitation with inconsistency for how long and why?. Veterinary parasitology, 138(3-4), pp.169-178.

[24] Kebede, S., Menkir, S. and Desta, M., 2014. On farm and Abattoir study of Lungworm infection of small ruminants in selected areas of Dale District, Southern Ethiopia. International Journal of Current Microbiology and Applied Science, 3(4), pp.1139-1152.

[25] Kouidri, M., S. Selles, A. Mohammed and S.A. Abdelhadi, 2013. Lungworm Infections in Goats Slaughtered in Alger. Glob. Vet., 11: 293-296.

[26] Mekonen A. Fromsa, A. and Ebuy, Y., 2011. Study on the prevalence of lungworm infection in small ruminants in Gondar town, Ethiopia. J. Anim. Vet. Adv, 10, pp.1683-1687.

[27] Radostits, O.M., Gay, C., Blood, D.C. and Hinchclift, K.W. Diseases associated with helminthes parasites. In: Veterinary Medicine, a text book of the disease of cattle, sheep, pigs, goats and horse. 9th ed. London: Harcourt publishers Ltd: 2000, p. 1564-1569.

[28] Sissay, A., 1996. Preliminary study on the prevalence of ovine lungworm infection in and around Bahir Dar. DVM thesis, Faculty of Veterinary Medicine, Addis Ababa University Debreziet, p.36.

[29] Teffera, S., 1993. Prevalence of ovine lung worms around Dessie and Kombolcha. DVM Thesis, Addis Ababa University, Debrezeit, Ethiopia.

[30] Terefe, Y., Tafess, K., Fekadie, G. and Kebede, N., 2013. Prevalence of lungworm infection in small ruminants in North Gondar zone, Amhara National Regional State, Ethiopia. Journal of Parasitology and Vector Biology, 5(4), pp.40-45. 
[31] Thrusfield M Survey in Veterinary epidemiology. $2^{\text {nd }}$ ed., Black well Ltd., Cambridge, USA2005; Pp. 178198.

[32] Tolosa, T., Tefera, M., Deneke, Y., Gashaw, A., Supré, K. and De Vliegher, S., 2010 Milk Production and Marketing system in Jimma Town, South-western Ethiopia.

[33] Urquhart, H.M., Armour, J., Duncan, J.L., Dunn, A.M. and Jennings, F.W., 1996. Veterinary parasitology. 2nd ed. London: Black well science Ltd: 1996, Pp. 301-309. 13. Schneider, T. Helminthes of respiratory system. In: veterinary medicine parasitology vol.5 voll standing auflage. Parey bush vet log. Berlin: 2000, p. 193-198.

[34] Van Wyk, J.A., Cabaret, J. and Michael, L.M., 2004. Morphological identification of nematode larvae of small ruminants and cattle simplified. Veterinary parasitology, 119(4), pp.277-306.

[35] Wilsmore T (2006) Diseases of small ruminants in Ethiopia, the veterinary epidemiology and economics research unit school of agriculture's policy and development the University of Read, UK, pp. 67-72.

[36] Yimer A, Desie A (2016) Epidemiological Studies on Ovine Lungworm Species in Northern Ethiopia. J Vet Sci Technol 7: 387

Citation: Mukarim Abdurahaman. et.al, "Prevalence of Ovine Lung Worm in and around Jimma, South West Ethiopia", International Journal of Research Studies in Biosciences (IJRSB), vol. 6, no. 5, pp. 24-32, 2018. http://dx.doi.org/10.20431/2349-0365.0605004

Copyright: ( $) 2018$ Authors. This is an open-access article distributed under the terms of the Creative Commons Attribution License, which permits unrestricted use, distribution, and reproduction in any medium, provided the original author and source are credited. 